IZA DP No. 4864

Can Training Programs or Rather Wage Subsidies

Bring the Unemployed Back to Work?

A Theoretical and Empirical Investigation for Germany

Renate Neubäumer

April 2010 


\title{
Can Training Programs or Rather Wage Subsidies Bring the Unemployed Back to Work? A Theoretical and Empirical Investigation for Germany
}

\author{
Renate Neubäumer \\ University of Koblenz-Landau \\ and IZA
}

Discussion Paper No. 4864

April 2010

IZA

P.O. Box 7240

53072 Bonn

Germany

Phone: $+49-228-3894-0$

Fax: +49-228-3894-180

E-mail: iza@iza.org

Any opinions expressed here are those of the author(s) and not those of IZA. Research published in this series may include views on policy, but the institute itself takes no institutional policy positions.

The Institute for the Study of Labor (IZA) in Bonn is a local and virtual international research center and a place of communication between science, politics and business. IZA is an independent nonprofit organization supported by Deutsche Post Foundation. The center is associated with the University of Bonn and offers a stimulating research environment through its international network, workshops and conferences, data service, project support, research visits and doctoral program. IZA engages in (i) original and internationally competitive research in all fields of labor economics, (ii) development of policy concepts, and (iii) dissemination of research results and concepts to the interested public.

IZA Discussion Papers often represent preliminary work and are circulated to encourage discussion. Citation of such a paper should account for its provisional character. A revised version may be available directly from the author. 


\section{ABSTRACT \\ Can Training Programs or Rather Wage Subsidies Bring the Unemployed Back to Work? A Theoretical and Empirical Investigation for Germany ${ }^{\star}$}

Our paper investigates the relative effects of wage subsidies and further vocational training on the subsequent employment prospects of previously unemployed program participants. First, we outline a theoretical approach based on a firm's hiring decision. For the relative effectiveness of both labor market programs the assumption concerning the formation of human capital is crucial and leads to competing hypotheses for the medium and long term. On the assumption that wage subsidies have no effect on human capital they improve individuals' employment prospects less than training programs. Contrariwise, on the assumption that the formation of human capital on subsidized jobs equals that by formal training subsidization has the same employment effect as a training program. Second, we test the two hypotheses empirically, using a large administrative data set from Germany and statistical matching techniques. Our treatment groups consist of unemployed persons taking up subsidized employment or entering a further vocational training program, respectively, during March 2003. To exclude unemployment after program end we estimate the effect of keeping a subsidized job versus participating in training and taking up a job immediately afterwards. The results strongly support the latter of our competing hypotheses: Previously subsidized individuals and trained individuals who found a job immediately afterwards have the same employment rates. This leads to the conclusion that firms value training on a subsidized job as much as formal training programs.

JEL Classification: J68, J64, J65

Keywords: evaluation of active labor market programs, training programs, wage subsidies, propensity score matching

Corresponding author:

Renate Neubäumer

University of Koblenz-Landau

Institute of Social Sciences

Department of Economics

August-Croissant-Straße 5

D-76829 Landau

Germany

E-mail: neub@uni-landau.de

\footnotetext{
* I am grateful to Gesine Stephan for very helpful discussions and for the empirical estimates as well as to the SWA2 unit of the German Public Employment Service that provided the data. Richard B. Freeman, Edward Glaeser and Guido Imbens were particularly helpful, when I wrote a previous version of this paper during my stay as a visiting scholar at Harvard University. I thank them for their inspiring comments and suggestions.
} 
Table of contents

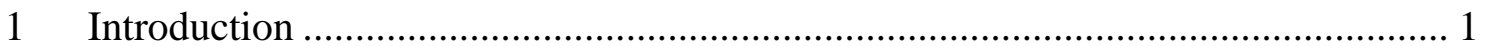

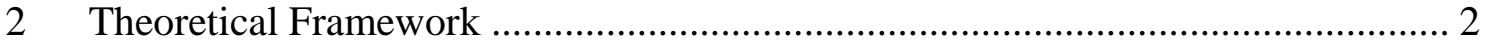

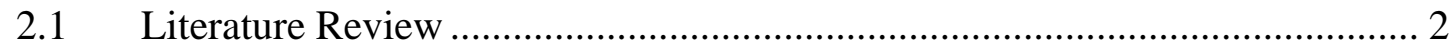

2.2 A Firm's Decision to Hire - or not to Hire........................................................ 3

2.3 Hiring Decisions with Active Labor Market Programs .................................... 4

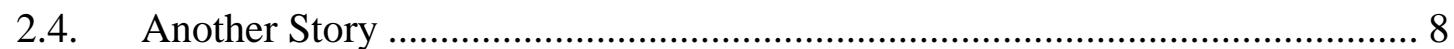

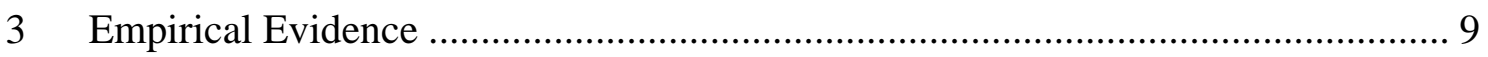

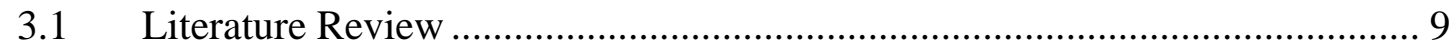

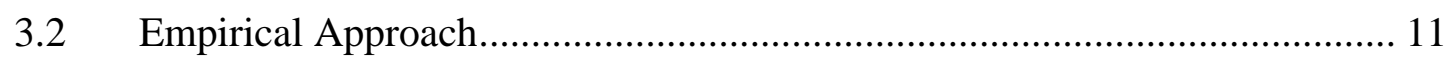

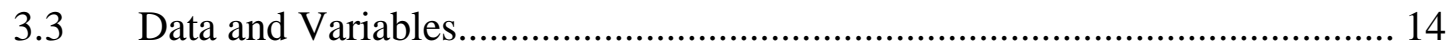

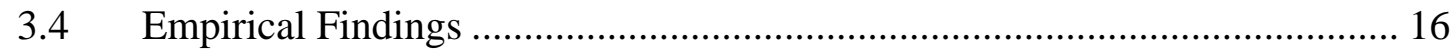

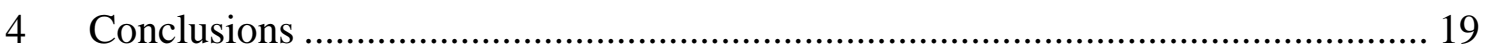

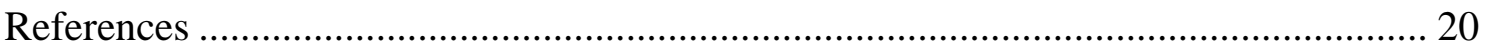

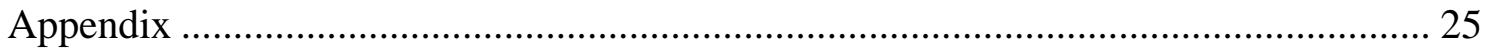




\section{Introduction}

In Germany, considerable funds are devoted to active labor market programs that should support the integration of unemployed persons into the labor market. As a rule of thumb, the German Federal Employment Agency and the German Federal Government expenditures for active labor market programs have equaled around 40 percent of the expenditures on passive unemployment benefits and social assistance in past years. Thus Wunsch and Lechner (2008) were not the only ones to raise the question "What Did All the Money Do?”. During the last decade, a steadily increasing literature on program evaluation has evolved. For Germany, a number of microeconometric studies based on large process generated data sets estimated the average effects of program participation on participants.

We are interested in particular in wage subsides and further vocational training programs, using a comparative approach. Recent findings showed that vocational training programs for the unemployed and wage subsidies had considerable lock-in effects in the short run, but were fairly successful in the long run in bringing participants back to regular employment (Lechner et al., 2005; 2007, Fitzenberger et al., 2006, Fitzenberger and Völter, 2007, Jaenichen and Stephan, 2009). However, as Caliendo and Steiner (2005, 36) explained , "Present studies estimate the success of a certain (labor market) program on the basis of statistical models without formulating economic hypothesis explicitly". Therefore, we develop a theoretical framework to compare the expected effects of training and wage subsidy programs on the employment prospects of participants, and test the presumptions of the model empirically. Although Lechner (1999), Imbens (1999) and Gerfin and Lechner (2002) extend Rubin's model to pairwise program comparisons, comparative empirical studies of active labor market programs are still sparse for Germany.

In more detail, our paper contributes to the literature by first presenting a theoretical approach that discusses the effects of two major active labor market programs - wage subsidies and further training programs - on the employment prospects of participants. The model draws attention in particular to the role of hiring decisions of firms and to the formation of human capital by training programs and by training on subsidized jobs. Second, we estimate relative average treatment effects on the differentially treated for 
both programs (and conduct also a comparison with non-participants). To account for unemployment after labor market programs we conduct comparisons not only of all unemployed but also of unemployed persons taking-up or keeping a job after program end (which is new in literature). For this purpose, we use German data to analyze persons who entered one of the programs in March 2003. Outcome variables are cumulated days spent in regular employment during the 3.5 years after program's start and the share in regular employment at the end of the observation periods.

The paper proceeds as follows: Section 2 presents the theoretical framework underlying our analysis, while Section 3 describes the empirical method data as our findings. Both Sections include also a short literature review. Finally, Section 4 summarizes and draws some conclusions.

\section{Theoretical Framework}

\subsection{Literature Review}

Recent theoretical analyses of active labor market programs are either of microeconomic nature or at least micro-founded. One branch of the related literature models labor market imperfections arising from wage setting in an economy (e.g. efficiency models, insider-outsider models), and deducts quasi-equilibrium unemployment (Snower, 1994, 1997, Layard, 1997). Mortensen and Pissarides (1994, 2003) developed a searchand match equilibrium, also taking into account the effects of wage subsidies. Their partial model - excluding factor and good markets - has been expanded for instance by Boone and van Ours (2004), Cardullo and van der Linden (2006) and Oskamp and Snower (2007) to analyze the implications of different active labor market programs, like public employment services, wage subsidies and training programs, on unemployment.

Calmfors et al. (2002) and Calmfors (1994) conducted a comprehensive analysis of the - intended and unintended - effects of active labor market policy by using a modified version of the theoretical framework for analyzing equilibrium real wages and unemployment, as laid out by Layard et al. (1991). In their micro-funded framework active labor market policy has the following major effects: It improves the matching-process (Mortensen and Pissarides, 1994, Pissarides, 2000) and increases the productivity of job seekers, especially through training programs. It strengthens the competition for avail- 
able jobs by augmenting and preserving the skills of unemployed individuals and maintaining the motivation to actively seek work (Layard et al., 1991, Nickell and Layard, 1999) and it improves the allocation of the work force from low-productivity sectors to expanding high-productivity sectors, especially through training programs and other mobility-enhancing programs. However, it may also crowd out regular labor demand, and increase the use of subsidized employment. Finally, it may induce additional wage pressure, because it increases welfare during unemployment.

Our theoretical approach applies to the individual hiring decisions of firms and to the employment prospects of program participants. With that partial analytic approach we can examine the direct implications of active labor market programs, like decreasing costs or increasing productivity of employees. We cannot, however, identify indirect effects, like dead weight losses and substitution effects or improving the allocation of the workforce. The model is in the tradition of Albach (1996), who models firms' hiring decisions by taking into account transaction cost, settling-in and further training costs, and dismissal costs and by interpreting hiring as an investment. Sadowski (2002) develops a similar approach of a firm's demand of human resources assuming quasi-fixed labor costs; Neubäumer (2006) takes into account all costs and revenues of labor contracts.

\subsection{A Firm's Decision to Hire - or not to Hire}

Building on the theoretical approaches of Albach (1996) and Neubäumer (2006) we model a firm's hiring as an investment decision in the case of quasi-fixed costs per employee . Assume that the firm maximizes its expected profit; the discount rate is given by r. A firm hires a worker, taking into account transaction costs for search and selection $\left(\mathrm{C}_{0}\right)$ in period 0 as well as settling-in costs $\left(\mathrm{C}_{1}\right)$, i.e. the difference between wage and marginal productivity $\left(\mathrm{w}_{1}-\mathrm{Q}_{1}\right)$, in period 1 . The marginal productivity in period 1 and in further periods is determined by a set of characteristics of the firm, the job and the employee.

The present value of a worker (PV) is the result of his net revenues $\left(\mathrm{w}_{\mathrm{i}}-\mathrm{Q}_{\mathrm{i}}\right)$ in period 2 thru n. Therefore we are particularly interested in the duration of the employment relationship. On the one hand firms differ by the number of periods (n) they intend to employ a worker. $\mathrm{n}$ will be lower if a firm requires external flexibility, for instance because 
it is exposed to economic shocks. Furthermore n depends on the need of firm-specific human capital for a certain job, i.e. the same firm can have jobs with a high $\mathrm{n}$ or jobs with a low n. On the other hand the probability that this intended duration can be realized (P) depends on an employee's qualification and behavior: He will be dismissed by the firm if he performs badly, but he might also quit the job himself.

A firm's condition for hiring a particular worker in is given by

$$
\mathrm{P} \cdot \underbrace{\sum_{\mathrm{i}=2}^{\mathrm{n}} \frac{\mathrm{Q}_{\mathrm{i}}-\mathrm{w}_{\mathrm{i}}}{(1+\mathrm{r})^{\mathrm{i}}}}_{\mathrm{PV}}-\mathrm{C}_{0}-\left(\mathrm{w}_{1}-\mathrm{Q}_{1}\right) \geq 0
$$

\section{Including the effects of unemployment}

What are the impacts of unemployment, especially of a longer period of joblessness? Unemployment depreciates previously acquired human capital and has an adverse effect on workers motivation and self-esteem.

Therefore we firstly assume that unemployment raises the settling-in costs $\left(\mathrm{w}_{1}-\mathrm{Q}_{1}\right)$ as the marginal productivity in period 1 decreases with the duration of unemployment $(\mathrm{u})$ $\left(\mathrm{dQ}_{1} / \mathrm{du}<0\right) .{ }^{1}$ Second, we assume that the probability of reaching the intended duration of the employment relationship decreases with the duration of unemployment $(\mathrm{dP} / \mathrm{du}<0)$. Finally, we assume that wages $\mathrm{w}_{\mathrm{i}}$ are given and do not vary with the previous duration of unemployment, as many German firms have to pay collective agreed wages to union members and voluntarily pay them to non members, as well . In addition, differentiating wages by unemployment duration might be considered as "unfair”.

Thus a firm's condition for hiring an unemployed individual is

$$
\mathrm{P}(\underline{\mathrm{u}}) \cdot \mathrm{PV}-\mathrm{C}_{0}-\left(\mathrm{w}_{1}-\mathrm{Q}_{1}(\underline{\mathrm{u}})\right) \geq 0 \text {. }
$$

\subsection{Hiring Decisions with Active Labor Market Programs}

In the next step we consider the effects of active labor market programs. A wage subsidy is paid to employers during period 1 to compensate for higher settling-in costs if they hire a previously unemployed person. A follow-up period of further employment is

1 To keep our model simple we assume that unemployment does not have an effect on the productivity of later periods. 
obligatory after the expiration of the subsidy; otherwise the received subsidy has to be reimbursed by the firm. If such a settling-in subsidy $\left(\mathrm{s}_{1}\right)$ is paid, a firm's hiring condition for subsidized workers is given by

$$
\mathrm{P}(\underline{\mathrm{u}}) \cdot \mathrm{PV}-\mathrm{C}_{0}-\left(\mathrm{w}_{1}-\mathrm{Q}_{1}(\underline{\mathrm{u}})\right)-\mathrm{s}_{1} \geq 0 \text {. }
$$

The subsidy will compensate for the adverse effects of unemployment as long as

$$
\mathrm{S}_{1} \geq-(\underbrace{\frac{\partial \mathrm{Q}_{1}(\mathrm{u})}{\partial \mathrm{u}}}_{-}+\underbrace{\frac{\partial \mathrm{P}(\mathrm{u})}{\partial \mathrm{u}} \cdot \mathrm{PV}}_{\text {I: short term }}) .
$$

A wage subsidy will thus induce a firm to hire an unemployed individual for a particular job (with an associated intended duration of employment) if the wage subsidy covers the reduction of productivity in period 1 (I) and the risk induced through the shorter expected value of P (II). Therefore we assume that subsidized workers are more often hired for jobs that are intended to be short, i.e. for jobs with little need of firm-specific human capital and/or in firms requiring a high external flexibility. Even then the wage subsidy has to be at least as large as the reduction of the marginal productivity in period 1 (I). Hence, even with a subsidy, long-term unemployed often will not find a job.

Training programs (q) are aimed at maintaining and extending the vocational qualifications of unemployed and thus can be regarded as a human capital investment. Furthermore, participating in a qualification program and completing it may serve as a signal of motivation and endurance. Therefore we assume that training decreases a worker's settling-in cost, raises his marginal productivity in period 2 thru $n$ and increases the probability of reaching the intended duration of the employment relationship. To simplify the model , we assume that training does not have an impact on the wage rate of the formerly unemployed person. Thus the hiring condition changes to

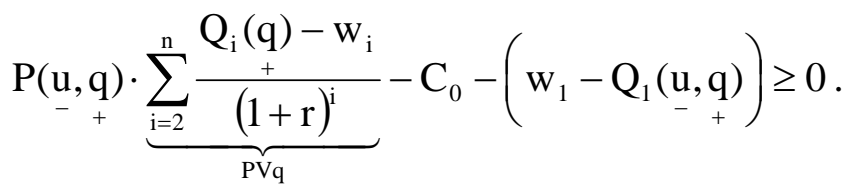

Note that all three (positive) effects depend on the quality of the training program (q), i.e. the adequacy of the content taught , the qualification and engagement of the instruc- 
tors and the trainability and motivation of the participants. Furthermore, the firm's valuation of the program quality is important; the firm has to be convinced that the program has the desired effects.

Training will thus compensate for the adverse effects of unemployment as long as

$$
(\underbrace{\frac{\partial \mathrm{Q}_{1}(\mathrm{u}, \mathrm{q})}{\partial \mathrm{q}}+\underbrace{\frac{\partial \mathrm{Q}_{1}(\mathrm{u}, \mathrm{q})}{\partial \mathrm{u}}}_{-}}_{\text {I: short term }}+\underbrace{\frac{\partial \mathrm{P}(\mathrm{u}, \mathrm{q})}{\partial \mathrm{q}} \cdot \mathrm{PVq}}_{\text {II: medium to long term }}+\underbrace{\frac{\partial \mathrm{P}(\mathrm{u}, \mathrm{q})}{\partial \mathrm{u}} \cdot \mathrm{PVq}}_{+}+\underbrace{\mathrm{P} \cdot \frac{\partial \mathrm{PVq}}{\partial \mathrm{q}}}_{+}) \geq 0 .
$$

First, a training program reduces the deduction of productivity in period 1 by unemployment (I). This short term effect is particular relevant for jobs intended to end after a short employment period. Secondly, training increases the present value and the expected probabilityof realizing the intended employment duration. This medium to long term effect (II) is more important for long-term positions . It is positive in most cases. Otherwise $\partial \mathrm{P}(\mathrm{u}, \mathrm{q}) / \partial \mathrm{u}$ not only has to be larger than $\partial \mathrm{P}(\mathrm{u}, \mathrm{q}) / \partial \mathrm{q}$, but the resulting effect also has to compensate for the effect of the higher present value induced by the training. (Very poor training quality could be a reason for this .)

Finally, comparing subsidized and trained unemployed persons, the hiring condition implies that a firm will prefer a subsidized worker as long as

$$
\underbrace{\mathrm{s}_{1}-\frac{\partial \mathrm{Q}_{1}(\mathrm{u}, \mathrm{q})}{\partial \mathrm{q}}}_{\text {I: short term }} \geq \underbrace{\frac{\partial \mathrm{P}(\mathrm{u}, \mathrm{q})}{\partial \mathrm{q}} \cdot \mathrm{PVq}+\mathrm{P} \cdot \frac{\partial \mathrm{PVq}}{\partial \mathrm{q}}}_{\text {II: medium to long term }} .
$$

Our model suggests that firms with high need for external flexibility and/or with jobs with low firm-specific human capital prefer subsidized workers as the wage subsidy $\left(\mathrm{s}_{1}\right)$ is usually higher than the productivity effect of the training program during the settlingin period (positive short term effect I). ${ }^{2}$ If $\mathrm{n}$ is low, medium and long term effects will be small and inconsequential (I > II). Contrariwise, a firm with permanent jobs, e.g. due

2 The productivity effect of the training in period 1 is limited as a low productivity during settling-in results not only from a low motivation and trainability of further unemployed but also from his lack of firm-specific human capital. 
to high firm-specific human capital and minor external fluctuations, will prefer hiring participants in training programs as the additional present value and the higher probability to realize this present value will over-ride the short term effect (II > I).

\section{Including search unemployment}

Nearly all subsidized workers are further employed after the subsidization period due to the obligatory follow-up period, while participants of training programs often have a period of search unemployment $\left(u_{s}\right)$ after program end. We assume that the human capital gained by training is depreciated to $\mathrm{q}_{\mathrm{s}}$ if followed by search unemployment as a part of the human capital will be lost, if the newly won knowledge and abilities are not applied and strengthened and the renewed unemployment has a demoralizing effect.

Thus a firm will prefer an unemployed with a wage subsidy to an (otherwise similar) unemployed with training and search unemployment as long as

$$
\underbrace{\mathrm{s}_{1}-\frac{\partial \mathrm{Q}_{1}\left(\mathrm{u}, \mathrm{q}_{\mathrm{s}}\right)}{\partial \mathrm{q}_{\mathrm{s}}}}_{\text {I: short term }} \geq \underbrace{\frac{\partial \mathrm{P}\left(\mathrm{u}, \mathrm{q}_{\mathrm{s}}\right)}{\partial \mathrm{q}_{\mathrm{s}}} \cdot \mathrm{PVq}_{\mathrm{s}}+\mathrm{P} \cdot \frac{\partial \mathrm{PVq}_{\mathrm{s}}}{\partial \mathrm{q}_{\mathrm{s}}} \mathrm{q}_{\mathrm{s}}}_{\text {II: medium to long term }} .
$$

Now, a firm with jobs intended to be short term will prefer workers with wage subsidies even more (I >> II). For a firm with permanent jobs $q_{s}$ is crucial, i.e. how much the human capital won by training is depreciated by search unemployment. If qs has become small and hence the additional present value and the higher probability to realize this present value is small, the positive medium and long term effect of training will not exceed the short term effect of a subsidy (II < I).

Against that theoretical background we formulate the following hypotheses:

1) Recipients of wage subsidies have better employment prospects than participants of training programs, in the short run,

2) Participants of training programs whofind a job immediately after the program ends have better employment prospects than recipients of wage subsidies in the mediumto long-term.

(The second hypothesis might apply in a minor degree if participants of training programs with search unemployment are included.) 


\subsection{Another Story}

In our previous model the human capital of formerly unemployed people is developed by formal training only. However , we now assume that learning by doing, i.e. training on a (subsidized) job, leads to more knowledge and ability . The amount of human capital gained depends on the quality of the on the job training $\left(\mathrm{q}_{\mathrm{toj}}\right)$.

First, we assume that the additional human capital increases the productivity in periods 2 to $\mathrm{n}$ and hence the (expected) present value $\left(\mathrm{PV}_{\mathrm{toj}}\right)$. Secondly, we assume that the on the job training increases the probability of realizing the intended duration of employment by the same amount as a training program $\left(\partial \mathrm{P}\left(\mathrm{u}, \mathrm{q}_{\mathrm{toj}}\right) / \partial \mathrm{q}_{\mathrm{toj}}=\partial \mathrm{P}(\mathrm{u}, \mathrm{q}) / \partial \mathrm{q}\right)$.

Thus a firm will now prefer to hire an unemployed individual with a wage subsidy to an otherwise similar unemployed with training (and without search unemployment) as long as

$$
\underbrace{\mathrm{s}_{1}-\frac{\partial \mathrm{Q}_{1}(\mathrm{u}, \mathrm{q})}{\partial \mathrm{q}}}_{\text {I: short term }}+\underbrace{\mathrm{P} \cdot \frac{\partial \mathrm{PVq}_{\mathrm{toj}}}{\partial \mathrm{q}_{\mathrm{toj}}}-\mathrm{P} \cdot \frac{\partial \mathrm{PVq}}{\partial \mathrm{q}}}_{\text {II: medium to long term }} .
$$

This leaves the short term effect (I) unchanged whereas the medium- to long-term effect depends on the firms' valuation of the quality of the two training schemes:

- If firms expect, that the quality of the on the job training is comparable to the quality of the formal training, the medium- to long-term effect (II) turns to zero. Therefore, it is likely that firms do not prefer participants of training programs to recipients of wage subsidies for permanent jobs. Subsidized workers do not have a higher risk of dismissal.

- If firms value the quality of the formal training much higher than the quality of the on the job training, the medium to long term effect (II) is negative and firms with permanent jobs will prefer to hire participants of training programs. (The result is approximately the same as if we do not include the effects of on the job training in our model.)

The assumption of training on subsidized jobs has to be tested empirically. Therefore we have to add a competing hypothesis and will test the following hypotheses: 
1) Recipients of wage subsidies have better employment prospects than participants of training programs, in the short run,

2) Participants of training programs who find a job immediately after the program ends have better employment prospects than recipients of wage subsidies, medium- to long-term.

against

3) Recipients of wage subsidies have the same (or even better) employment prospects as participants of training programs who find a job immediately after the program end, medium- to long-term.

(If we include program participants with unemployment the advance of participants in training will be lower (hypothesis 2) or recipients of wage subsidies have better employment prospects than participants in training (hypothesis 3).)

\section{Empirical Evidence}

\subsection{Literature Review}

In Germany, participation in further vocational training programs seems to increase employment prospects in the long-term, while medium-term results are ambiguous . Lechner et al. (2005, 2007), Fitzenberger et al. (2006) and Fitzenberger and Völter (2007) analyzed the long-run effects up to seven years after program entry, focusing mainly on unemployment entries in 1993/94. In the long run, they generally found positive effects of further vocational training. However, because program effects are rather weak and participants search for employment less during training (lock-in effect) it may take some time until the estimated effect turns positive. For program entries during the years 2000 to 2002 and medium-term effects around 2 to 2.5 years the evidence is mixed: Rinne et al. (2007) obtained middle-term positive effects of program participation on the employment possibilities in all subgroups investigated. Biewen et al. (2007) found positive short- and medium-term effects on employment rates of participants for programs in West Germany (but not in East Germany) and particular groups of unemployed. Wunsch and Lechner (2008) as well as Lechner and Wunsch (2006) estimated 
that further vocational training had mostly negative or insignificant effects on employment rates of participants.

A large number of studies have estimated the impact of targeted wage subsidies on the employment prospects of participants, compared to unemployed non-participants. Most authors constructed comparison groups of similar, but non-subsidized individuals using statistical matching techniques and non-experimental data. For Germany, Jaenichen (2002, 2005) and Jaenichen and Stephan (2009) used this approach and showed that participants in different types of targeted wage subsidy schemes subsequently much higher employment rates than similar unemployed persons, who did not take up a subsidized job. In West Germany, Ruppe (2009) found that subsidies decreased the risk of ending an employment relationship considerably, resulting in higher survival rates and longer tenure of previously subsidized employment relationships. ${ }^{3}$ Evidence for Britain (Dorsett 2001) and Sweden (Sianesi 2008, Carling and Richardson 2004, Fredriksson and Johansson 2004, Forslund et al. 2004) suggested that wage subsidies had a positive effect on employment probabilities of the participants. Turning to the few results from social experiments on subsidy vouchers, Burtless (1985) found that unemployed persons with a voucher were less likely to find employment than job-seekers without vouchers. However, Dubin and Rivers (1993) obtained an increased probability of reemployment for the treated groups, when taking into account self-selection forvoucher usage.

Boockmann et al. (2007) investigated the effects changes in the legislation regarding German wage subsidies and concluded that increases in subsidized employment were mostly absorbed by deadweight losses. Hartmann (2004) conducted a comprehensive study of the hiring behavior of firms. Thereby he tried to estimate the amount of deadweight loss by asking firms if they would have hired the same person without the support of a subsidy. For the program under consideration in our study, firms answered that around 40 to 60 percent of subsidized persons would have been hired anyway without the help of the subsidy (p. 93). These results are in line with findings of the implementation study from a survey of 34 firms, presented in ZEW et al. (2005, p. 140 ff.).

3 That supports our assumption of training on subsidized jobs causing the result that firms do not prefer participants of training programs to recipients of wage subsidies for permanent jobs. 
Comparisons across participants in further vocational training and unemployed taking up a subsidized job have not been presented for Germany yet. For Great Britain, Dorsett (2001) contrasted entries into subsidized employment, full-time education and training, an environmental task force or a voluntary sector that were different options within the New Deal Program for Young People. His main finding was that wage subsidies dominated all other options. For Switzerland, Gerfin and Lechner (2002) compared participation in nine different programs. They showed that temporary wage subsidies paid to employees - paid in order to compensate income-losses in comparison to former times of employment - has been most efficient in integrating participants into regular employment. Gerfin et al. (2004) contrasted employment programs in non-profit organizations and temporary wage subsidies; again the latter were more effective. For Sweden, Sianesi (2008) compared participation in six major programs. Employment subsidies performed best by far; they were followed by trainee replacement and labor market training. Sianesi (2008) summarizes as a main result of many micro studies that the more a program resembles regular employment in the competitive sector, the more it will benefit its participants.

Jaenichen and Stephan (2009) point out that regarding wage subsidies, an argument against the matching approach might be that not solely labor market outcomes after receiving a subsidy are observed, but rather outcomes of a subsidy in combination with a job offer. Hence the result that unemployed taking up a subsidized job have better labor market prospects than participants of training programs could be due to the fact that some of the latter suffer from search unemployed after program end. Therefore we do the comparisons not only of all participants of the two programs but also of participants who are employed after program end. That type pf comparison has not been conducted before either.

\subsection{Empirical Approach}

We want to estimate the average effects on the labor market outcomes of the differentially treated (ATDT). The underlying idea is based on the potential outcomes model (Rubin, 1974) that has been extended by Imbens (1999) and Lechner (1999) to multiple states: An individual can potentially be in different states, while the outcome variable of interest may differ between these states. In our analysis the different states will be no 
program entry, an entry into subsidized employment or an entry in a training program during March 2003. Because we cannot observe the average counterfactual outcome that members of one group would have had, if they had received a different treatment instead, we have to find an adequate comparison group to attribute this counterfactual outcome. We assume that the value of the outcome variables for each person is not influenced by the actual participation of other persons (Stable Unit Treatment Value Assumption).

With non-experimental data, statistical matching techniques might be applied to find such a comparison group. The method has to take into account that assignment to a particular program, e.g. a qualification program, is no random event. In particular those individuals who expect to benefit most from training may enter the program. The identifying assumption of statistical matching is that no unobserved heterogeneity correlated with the selection into (particular) programs and with outcome variables remaining after accounting for a set of observable variables $\mathrm{X}$, which determine the participation decision as well as the expected success of a program. An estimate of the counterfactual outcome - for instance the outcome participants in training programs would have had after treatment with a wage subsidy - can then be based on individuals with similar observable characteristics $\mathrm{X}$ who in fact received a wage subsidy. In other words: Depending on $\mathrm{X}$, the outcome after participation in a particular program should not depend on the decision to join this program (Conditional Independence Assumption). However, the comparison can only be conducted for individuals who have - conditional on the variable vector $\mathrm{X}$ - a positive probability to be in each of both programs (Common Support Condition).

Against the background of our theoretical approach and the resulting hypotheses we estimate two scenarios, with different counterfactual situations: First, we estimate the effect of taking up a subsidized job versus participating in training and taking up a job afterwards (and also versus taking up non-subsidized employment). Second, we estimate the effect of taking up a subsidized job versus joining a training program with and without unemployment afterwards (and also versus remaining unemployed).

We choose comparison groups by means of propensity score matching. Rosenbaum and Rubin (1983) have shown that it is sufficient to match on the propensity score - the probability to join a program - to obtain the same probability distribution for treated 
and non-treated individuals. This is a useful simplification, since exact matching on a high-dimensional vector of X-variables would become a complex task. Similar properties hold true in a multiple treatment framework as well (Lechner, 1999). We estimate propensity scores using a probit model for each combination analyzed. Comparison group members are then chosen by radius matching (Dehejia and Wahba, 2002) with a caliper of 0.005: Participants are matched with "synthetic comparison persons", composed of a weighted equivalent of all persons falling within a radius of 0.005 their propensity score. The program impact is then estimated as the mean difference in the weighted outcomes of both groups. All estimates are performed using the STATAmodule psmatch2 (Leuven and Sianesi, 2003). Note that variance estimates for estimated treatment effects neglect that the propensity score itself has been estimated (Abadie and Imbens, 2006).

To test for the quality of the matching, we compute the mean standardized bias (MSB) (Rosenbaum and Rubin, 1983) between each treated group and its matched comparison group across all variables of $\mathrm{X}$. A lower value of the MSB indicates more similarity between the two groups. While no clear theoretical indication exists as to which remaining bias might be acceptable, Caliendo and Hujer (2005) summarize as a rule of thumb that most studies assess a reduction of the MSB after matching to 3 or 5 percent as sufficient. Black and Smith (2004) draw attention to the importance of common support. To analyze common support, we conduct two analyses. First, we compute the shares of individuals in the treatment and in the support group within common support. Second, we compute maximum weights to get an impression how heavily observations are utilized in constructing the counterfactuals. Finally, by conducting a Rosenbaum-bounds analysis we analyze how sensitive the estimated treatment effects are to a violation of the Conditional Independence Assumption. This analysis shows how strongly unobserved heterogeneity would have to influence the odds of differential assignment due to unobserved factors to undermine the results of the matching analysis. For this purpose we apply the stata module mhbounds (Becker and Caliendo, 2007) - used for nearest neighbor matching without replacement - to compute the Mantel-Haenszel statistics for the share in regular employment at the end of the observation period. 


\subsection{Data and Variables}

Our empirical analysis is based on the TrEffeR-data set (Stephan et al., 2006). This administrative data set has been constructed for the monitoring purposes of the German Public Employment Service. While the TrEffeR data set is not available for public use, it is composed of the same data flows as the Integrated Employment Biographies (IEB) of the Institute for Employment Research (Hummel et al., 2005). The version utilized here merges data flows from the distinct computer based operative systems of the Public Employment Service on periods of registered job search, registered unemployment, participation in labor market programs and employment for the period from 2000 to 2007. Our complete sample covered all program entries during March 2003 as well as a random 10-percent-sample of the unemployment stock during this month. For our analysis, we restrict the sample to West Germany and to individuals of age 25 to 54 who were unemployed for no longer than one year in March 2003 and have not entered a program until this time during their current unemployment spell.

For the ease of exposition we concentrate on individuals entering one of two program variants during March 2003, which can be seen as most closely matched to our theoretical approach and include only participants with a completed duration of up to 6 months: First, we analyze a variant of wage subsidies that compensates firms for settling-in costs $^{4}$. These subsidies are paid for a limited time period to employers hiring an unemployed person, to compensate for special training requirements at the workplace. Case managers in local employment agencies have latitude in the allowance decision as well as in the fixing of the amount (up to 30 percent of the monthly wage) and duration of the subsidy (at most 6 months). A follow-up period of further employment has been obligatory after the expiration of the subsidy. If a person is dismissed during subsidization or within this period, under specific conditions the employer could be asked to reimburse part of the subsidy. As has already been mentioned, the selection process of this scheme is driven by the fact that it requires consent of the unemployed person, the caseworker and the firm. Second, we investigate participants in further vocational training programs aimed at the provision of specific vocational skills, which may include

4 “Einarbeitungszuschuss bei Einarbeitung”. 
occupation-related training and general training. ${ }^{5}$ Direct training costs are covered by the Public Employment Service; furthermore, participants receive a subsistence allowance that usually equals the unemployment compensation. Since 2003 access to such further training programs is granted through training vouchers. Selection into training thus requires consent of the unemployed person, the caseworker as well as the training provider.

We estimate different program effects on participants using two outcome variables in each case. We compute i) cumulated days spent in regular employment during the 3.5 years after the program start in March 2003 and ii) shares in regular employment 3.5 years after the program start. In computing these outcome variables, times of subsidized employment and training are not interpreted as a "success", which results in a lock-in effect of programs. Our group of non-participants did not enter any program during March 2003, but might do so later, to avoid to condition on successful future outcomes (Sianesi 2008, Fredriksson and Johansson 2004). Outcome variables for nonparticipants are measured from March 15, 2003, and all individuals who had already left unemployment at this date were excluded from the sample.

Our model highlights in particular the importance of personal characteristics as education that will have an impact on an individual's productivity. In our estimates we account for a large number of variables that should be crucial for selection into programs as well as on labor market outcomes. Heckman and Smith (1999) show that it is important to account for the labor market history of individuals, while Heckman et al. (1999) demonstrate the relevance of regional labor market information. In particular, we include the following variables (all categorized as dummy variables): a) Sociodemographic characteristics, measured at the start of an unemployment spell: Age, marital status, nationality, education, degree of disability. b) Information on the kind of benefit receipt. c) Unemployment duration in current spell: Months before program entry in March 2003 for participants and months before March 15, 2003 for "waiting” non-participants. d) Employment-history in the two years preceding the analyzed unemployment spell, measured at the start of the unemployment spell: Former unemploy-

5 "Berufsbezogene übergreifende Weiterbildung, berufspraktische Weiterbildung oder berufliche Aufstiegsweiterbildung”. 
ment, participation in labor market programs, sanctions and periods of illness. e) Regional labor market situation: Performance cluster of the regional labor market (Blien et al., 2004).

For our comparison of subsidized workers with individuals who took up a job immediately after training, we restrict the analysis to program participants who were employed at least one day within one month after the end of the program. (Also, we compare both groups of program participants who found employment with "waiting" individuals who found a job within one month after March 15.)

\subsection{Empirical Findings}

Mean values of the explaining variables before matching are displayed in Table 1. While our analysis includes around 800 persons entering subsidized employment, we observe nearly 2,200 entries in training programs. The group of unemployed individuals not entering a program in March 2003 comprises around 130,000 persons. Table 1 shows that recipients of wage subsidies differ in fact from participants of training programs. They seem to be a "more positive selection" of program participants: They are younger than the average participant of a training program, have better qualifications, especially at a medium level, often receive more unemployment benefits, had less periods of sickness and have a shorter duration of unemployment.

Nine tenths of the recipients of wage subsidies, a quarter of participants of the training programs and every seventh "waiting" non-participant was employed within one month of the program's end, or after March 15, respectively. Subsidized and trained individuals who entered regular employment immediately after program participation are much more similar. They differ only - but by a smaller margin - regarding gender, vocational training and receipt of unemployment benefits. Also the characteristics of program participants and "waiting" individuals differ less. Nevertheless, in the latter group the percentage of older people, foreigners, and less qualified individual is still higher and the percentage of people unemployed up to 6 month is lower.

The results of our matching analysis of the two labor market programs are displayed in Table 2 and in Figure 1 and 2. Note that the average treatment effects of the differentially treated, the ATDTs, are asymmetric, because participants in different programs differ in their characteristics. 
Following up our hypotheses, we start with the results for program participants (and former unemployed) who keep or take up a job after the program ends (see "conditional on employment" in Table 2 and Figure 1). Comparing the effects of the two labor market programs, we find no significant differences in the employment prospects of participants in the wage subsidy and the training scheme; all ATDTs are insignificant. Figure 1 shows that subsidized workers have an advantage directly after the end of the program, but participants of training programs catch up after around 1.5 years. Mediumterm, both participant groups have nearly the same shares in regular employment.

These results strongly support our third hypothesis: Medium-term, recipients of wage subsidies have the same employment prospects as participants of training programs who find a job immediately after program end. This speaks for the assumption, that the formation of human capital by training on subsidized jobs is as high as the gain of human capital by formal training programs. Furthermore the results support our first hypothesis, that in the short run, recipients of wage subsidies have better employment prospects than participants of training programs.

The ATDTs of program participants relative to "waiting" individuals are slightly negative, in the short run (see Figure 1). This finding results from the fact that nonparticipants do not suffer from a lock-in effect. But program participants have slightly, but significant higher shares in regular employment after 3.5 years (about 6 percentage points). Furthermore, Figure 1 reveals that, in particular previously subsidized workers, but also previously trained workers, experience more stable employment relationships. Obviously, previous non-participants are more subject to seasonal unemployment. (This corresponds with the results of Hartmann (2004) showing that flexibility requirements deter firms from using subsidies and lead them to hire marginal or part-time employees instead.)

Without conditioning on employment, participants in the wage subsidy scheme are employed more often and for longer than participants in training programs: The majority of ATDTs is significantly different from zero (see Table 2). The main reason is that recipients of wage subsidies convey a relative advantage in terms of employment probabilities after programs have expired as their employment relationships usually do not end immediately after the expiration of the wage subsidy. 80 percent of subsidized jobs 
"survive" the period of subsidization and the follow-up period. In contrast, participants of training programs have to search for a new job during or after training (see Figure 2) and many of them have a period of search unemployment. Therefore recipients of wage subsidies have been in regular employment around 300 days more than similar participants of training programs during a period of 3.5 years. At the end of the observation period the difference in shares in regular employment still amounts to 16 percentage points. These results support the assumption that human capital can be gained by training on subsidized jobs as well as by formal training programs. Furthermore it becomes apparent that conditioning on employment is necessary to test the two competing hypotheses.

Finally, if we include individuals unemployed after program end, participants in both programs fare far better than non-participants (Table 2): After 3.5 years the share of subsidized individuals in regular employment is 27 percentage points higher than that of individuals in the state of "waiting"; for trained individuals the difference amounts to 12 percentage points. Furthermore, participants in both programs have spent more days in regular employment during the 3.5 years after program entry than non-participants. The effect is, again, remarkably larger for wage subsidy recipients (nearly 400 days) than for training participants (nearly 100 days).

Table 3 summarizes information on matching quality, features of common support and the possible importance of unobserved heterogeneity. When taken altogether, the statistics presented provide some confidence in the results of the matching analysis: First, the mean standardized bias (MSB) is considerably reduced after matching, to 1.9 or 1.8 , respectively, for differentially treated conditional on taking up employment and to 0.7 or 1.7 percent, respectively, for the full sample of differentially treated. The MSB is even lower for comparisons comprising non-participants. Second, the share of observations in common support never falls below 95 percent of treatment and comparison group members, which implies that our results refer to the majority of program members and that the majority of treatment group members have been taken into account when estimating counterfactual outcomes. By far the largest difference of an observation in the comparison group is found when estimating the relative effect of training compared to subsidization of similar persons, and amounts to 29. Regarding caseloads underlying our analysis (Table 1) this seems to be acceptable. Third, for estimated 
treatment effects on shares in regular employment at the end of the observation period, the last column shows how strongly unobserved heterogeneity would have to influence the odds of differential assignment due to unobserved factors to undermine the results of the matching analysis. For instance, to obtain insignificant or even negative treatment effects of participation in subsidized employment compared to training for the full sample, the impact of unobserved heterogeneity would have to increase the relative probability to obtain a subsidy by 110 percent.

\section{Conclusions}

What did all the money do that has been spent on active labor market programs in Germany? While the literature on program effectiveness has been steadily increasing, relatively few cross-program comparisons have been conducted for Germany yet, in particular none including wage subsidies. Furthermore previous comparisons did not exclude search unemployment, respectively did not condition on employment after program end.

Our paper presented first a theoretical approach based on a firm's hiring decision for comparing the effects of training programs and wage subsidies for the employment prospects of individuals. It led to the well-defined hypothesis that, in the short run, recipients of wage subsidies have higher employment rates than participants of training programs. In contrast, in the middle- to long-term the assumptions concerning the formation of human capital were crucial for the resulting hypotheses. On the assumption that wage subsidies have no effect on human capital they improve individuals' employment prospects less than training programs. However, on the assumption that the formation of human capital on subsidized jobs equals that by formal training subsidization has the same employment effect as a training program.

Second, we utilized process generated German data to test the theoretically deduced hypotheses empirically, i.e. we compared the effectiveness of participation in a wage subsidy scheme and a training program. Thereby we estimated with two different populations. As a start, we only allowed for individuals who kept a subsidized job or participated in training and took up a job immediately afterwards, i.e. we excluded (search) unemployment after end of program - which was new in literature. Afterwards, we used 
the whole sample and thus included unemployment after end of program - which was the usual procedure in literature.

In the short run subsidized individuals had higher employment rates than trained ones even if (search) unemployment after program end was excluded. (Both groups were after an initial lock-in period - more employed than non participants). This result is in line with our hypothesis for the short term. 3.5 years after program entry previously subsidized individuals and trained individuals who found a job immediately afterwards had nearly the same employment rates and the same number of cumulated days in employment (no significant ATDTs). That strongly supported the second of our competing middle-term hypotheses and led to the conclusion that firms value training on a subsidized job as much as formal training programs.

When we included unemployment after program end, subsidized individuals had significant higher employment rates than trained individuals in the short-term and after 3.5 years. (Furthermore employment rates of subsidized and trained workers were always higher than those of non-participants, who were especially subject to seasonal unemployment.)

Finally, it must be recalled that we could not identify the indirect effects of the different programs - neither with our model nor with our empirical results. As Layard et al. (1991, 481) emphasize, for a judgment of the welfare costs of a program much more has to be taken into account than simply employment rates: Beneath the program costs and the employment effects at the macro level, output benefits, psychic benefits and social costs, as well as the distributional incidence of active labor market programs have to be considered. They argue that important benefits from training are (hopefully) lifetime productivity gains for those trained and - because unemployment is one of the major sources in inequality in modern societies - the major distributional gain from any reduction in unemployment.

\section{References}

Abadie, A./Imbens, W. (2006), Large sample properties of matching estimators for average treatment effects, Econometrica 74, 235-267.

Albach, H. (1996), Die Beschäftigungsentscheidung der Unternehmungen - Arbeitslosigkeit aus betriebswirtschaftlicher Sicht, Discussion Papers FS IV 96-2, Wissenschaftszentrum Berlin. 
Becker, S.O./Caliendo, M. (2007), Sensitivity analysis for average treatment effects, Stata Journal 7, 71-83.

Biewen, M./Fitzenberger, B./Osikominu, A./Waller, M. (2007), Which program for whom? Evidence on the comparative effectiveness of public sponsored training programs in Germany, IZA Discussion Paper 2885.

Blien et al. (2004), Typisierung von Bezirken der Agenturen der Arbeit, Zeitschrift für Arbeitsmarktforschung 37, 146-165.

Boockmann, B./Zwick, T./Ammermüller, A./Maier, M. (2007), Do hiring subsidies reduce unemployment among the elderly? Evidence from two natural experiments, ZEW-Discussion Paper 07-001.

Boone, J./van Ours, J.C. (2004), Effective active labor market policies, IZA Discussion Paper 1335, Bonn.

Burtless, G. (1985): Are targeted wage subsidies harmful? Evidence from a wage voucher experiment, Industrial and Labor Relations Review, 39, 105-114.

Caliendo, M./Hujer, R. (2005), The microeconometric estimation of treatment effects - an overview, IZA Discussion Paper 1653, Bonn (Allgemeines Statistisches Archiv 90 (2006), 197212).

Caliendo, M./Steiner, V. (2005), Aktive Arbeitsmarktpolitik in Deutschland: Bestandsaufnahme und Bewertung der mikroökonomischen Evaluationsergebnisse, DIW Discussion Papers 515, Berlin.

Calmfors, L. (1994), Active labour market policy and unemployment - a framework for the analysis of crucial design features, OECD Labour Market and Social Policy Occasional Paper 15, Paris.

Calmfors, L./Forslund, A./Hemström, M. (2002): Does active labour market policy work? Lessons from the Swedish experiences, CESifo Working Paper 675, München.

Cardullo, G./van der Linden, B. (2006), Employment subsidies and substitutable skills: an equilibrium approach, IZA Discussion Paper 2073, Bonn.

Carling, K./Richardson, K. (2004), The relative efficiency of labour market programs: Swedish experience from the 1990s, Labour Economics 11, 335-354.

Dehejia, R.H./Wahba, S. (2002), Propensity score matching methods for nonexperimental causal studies, Review of Economics and Statistics 84, 151-161.

Dorsett, R. (2001), The new deal for young people: relative effectiveness of the options in reducing male unemployment, PSI Discussion Paper 7. 
Dubin, J.A./Rivers, D. (1993), Experimental estimates of the impact of wage subsidies, Journal of Econometrics 53, 219-242.

Fitzenberger, B./Osikominu, A./Völter, R. (2006), Get training or wait? Long-run employment effects of training programs for the unemployed in West Germany, ZEW Discussion Paper 06-39, Mannheim.

Fitzenberger, B./Völter, R. (2007), Long-run effects of training programs for the unemployed in East Germany, Labour Economics 14, 730-755.

Forslund, A./Johansson, P./Lindqvist. L. (2004), Employment subsidies - a fast lane from unemployment to work?, IFAU Working Paper 2004:18.

Fredriksson, P./Johansson, P. (2004), Dynamic treatment assignment - the consequences for evaluations using observational data, IZA Discussion Paper 1062.

Freeman, R. (2005), Labour market institutions without blinders: the debate over flexibility and labour market performance, NBER Working Paper 11286, Cambridge, Mass., April.

Gerfin, M./Lechner, M. (2002), A microeconometric evaluation of the active labour market policy in Switzerland, Economic Journal 112, 854-893.

Gerfin, M./Lechner, M./Steiger, H. (2004), Does subsidised temporary employment get the unemployed back to work? An econometric analysis of two different schemes, Labour Economics 12, 807-835.

Hartmann, J. (2004), Lohnkostenzuschüsse und Integration schwer vermittelbarer Personen in den ersten Arbeitsmarkt, Beiträge zur Arbeitsmarkt- und Berufsforschung 284, Nürnberg.

Heckman, J.J./Lalonde, R. L./Smith, J.A. (1999), The economics and econometrics of active labor market programs, in: Ashenfelter, O./Card, D. (eds.), Handbook of labor economics 3A, Amsterdam, 1865-2097.

Heckman, J.J./Smith, J.A. (1999), The pre-program earnings dip and the determinants of participation in a social program: implications for simple program evaluation strategies, Economic Journal 109, 313-348.

Hummel, E./Jacobebbinghaus, P./Kohlmann, A./Oertel, M./Wübbeke, C./Ziegerer, M. (2005), Stichprobe der Integrierten Erwerbsbiografien IEBS 1.0. FDZ-Datenreport 6/2005.

Imbens, G.W. (1999), The role of prospensity score in estimating dose response functions, NBER Technical Working Papers 237 (Biometrika 87 (2000), 706-710).

Jaenichen, U. (2002), Lohnkostenzuschüsse und individuelle Arbeitslosigkeit, Mitteilungen aus der Arbeitmarkt- und Berufsforschung 35, 327-351. 
Jaenichen, U. (2005), Lohnkostenzuschüsse und individuelle Beschäftigungschancen, in: Bellmann, L./Hübler, O./Meyer, W./Stephan, G. (eds.), Institutionen, Löhne und Beschäftigung, Beiträge zur Arbeitsmarkt- und Berufsforschung 294, Nürnberg, 137-156.

Jaenichen, U./Stephan, G. (2009, forthcoming), The effectiveness of targeted wage subsidies for hard-to-place workers, Applied Economics.

Katz, L.F. (1996), Wage subsidies for the disadvantaged, NBER Working Paper 5679, Cambridge MA (in: Freeman, R.B./Gottschalk, P. (eds.) (1998), Generating jobs: how to increase demand for less-skilled workers, New York, 21-53).

Layard, R. (1997), Preventing long-term unemployment: an econometric analysis, in: Snower, D.J./De la Dehesa (eds.), Unemployment policy: Government options for the labour market, Cambridge, 333-351.

Layard, R./Nickell, S./Jackman, R. (1991), Unemployment: Macroeconomic performance and the labour market, Oxford.

Lechner, M. (1999), Identification and estimation of causal effects of multiple treatments under the conditional independence assumption, IZA Discussion Paper 91 (in: Lechner, M./Pfeiffer; F. (eds.) (2001), Econometric evaluation of active labour market policies in Europe, Heidelberg, 43-58).

Lechner, M./Miquel, R./Wunsch, C. (2005), Long-run effects of public sector sponsored training in West Germany, IAB Discussion Paper 03/2005, Nürnberg.

Lechner, M./Miquel, R./Wunsch, C. (2007), The curse and blessing of training the unemployed in a changing economy: the case of East Germany after unification, German Economic Review.8, 468-509.

Lechner, M./Wunsch, C. (2006), Active labour market policy in East Germany: waiting for the economy to take off”, IAB Discussion Paper 20/2006.

Leuven, E./Sianesi, B. (2003), Psmatch2: Stata module to perform full Mahalanobis and propensity score matching, common support graphing and covariate imbalance testing. http://ideas.repec.org/c/boc/bo-code/s432001.htm .

Mortensen, D./Pissarides, C.A. (1994), Job creation and job destruction in a theory of unemployment, Review of Economic Studies 61, 397-415.

Mortensen, D./Pissarides, C.A. (2003), Taxes, subsidies and equilibrium labor market outcomes, in: Phelps, E., Designing inclusion: Tools to raise low-end pay and employment in private enterprise, Cambridge MA, 44-73. 
Neubäumer, R. (2006), Der gesetzliche Kündigungsschutz aus ökonomischer Sicht, Sozialer Fortschritt 55, 25-34.

Nickell, S./Layard, R. (1999), Labor market institutions and economic performance, in: Ashenfelter, O./Card, D. (eds.), Handbook of labor economics 3C, Amsterdam.

Oskamp, F./Snower, D.J. (2007), Comparing the effectiveness of training subsidies and employment vouchers, Manuskript vom 15. Februar 2007, Institut für Weltwirtschaft Kiel.

Pissarides, C. (2000), Equilibrium unemployment theory, MIT Press, Cambridge MA.

Rinne, U./Schneider, M./Uhlendorff, A. (2007), Too bad to benefit? Effect heterogeneity of public training programs, IZA Discussion Paper 3240.

Rosenbaum, P.R./Rubin, D.B. (1983), The central role of the propensity score in observational studies for causal effects, Biometrika 70, 41-55.

Rubin, D.B. (1974), Estimating causal effects of treatments in randomized and nonrandomized studies, Journal of Educational Psychology 66, 688-701.

Ruppe, K. (2009), Eingliederungszuschüsse und Betriebszugehörigkeit in Westdeutschland, Institute for Employment Research, Nuremberg, IAB Discussion Paper 6/2009.

Sadowski (2002), Personalökonomie und Arbeitspolitik, Stuttgart.

Sianesi, B. (2008), Differential effects of active labour market programs for the un-employed, Labour Economics 15, 392-421.

Snower, D.J. (1994), Converting unemployment benefits into employment subsidies, American Economic Review, Papers and Proceedings 84, 65-70.

Snower, D.J. (1997), The simple economics of benefit transfers, in: Snower, D.J./De la Dehesa (eds.), Unemployment policy: government options for the labour market, Cambridge, 163198.

Stephan, G./Rässler, S./Schewe, T. (2006), Das TrEffeR-Projekt der Bundesagentur für Arbeit. Die Wirkung von Maßnahmen aktiver Arbeitsmarktpolitik, Zeitschrift für ArbeitsmarktForschung 39, 447-465.

Wunsch, C./Lechner, M. (2008), What did all the money do? On the general ineffectiveness of recent West German labour market programmes, Kyklos 61, 134-174.

ZEW/IAB/IAT (2005), Zwischen- und Endbericht zum „Modul 1d: Eingliederungszuschüsse und Entgeltsicherung“ im Rahmen der Evaluation der Maßnahmen zur Umsetzung der Vorschläge der Hartz-Kommission, Arbeitspaket 1 (Wirksamkeit der Instrumente). 


\section{Appendix}

Table 1: Variable means of selected attributes $(0=$ no, $1=$ yes $)$ before matching

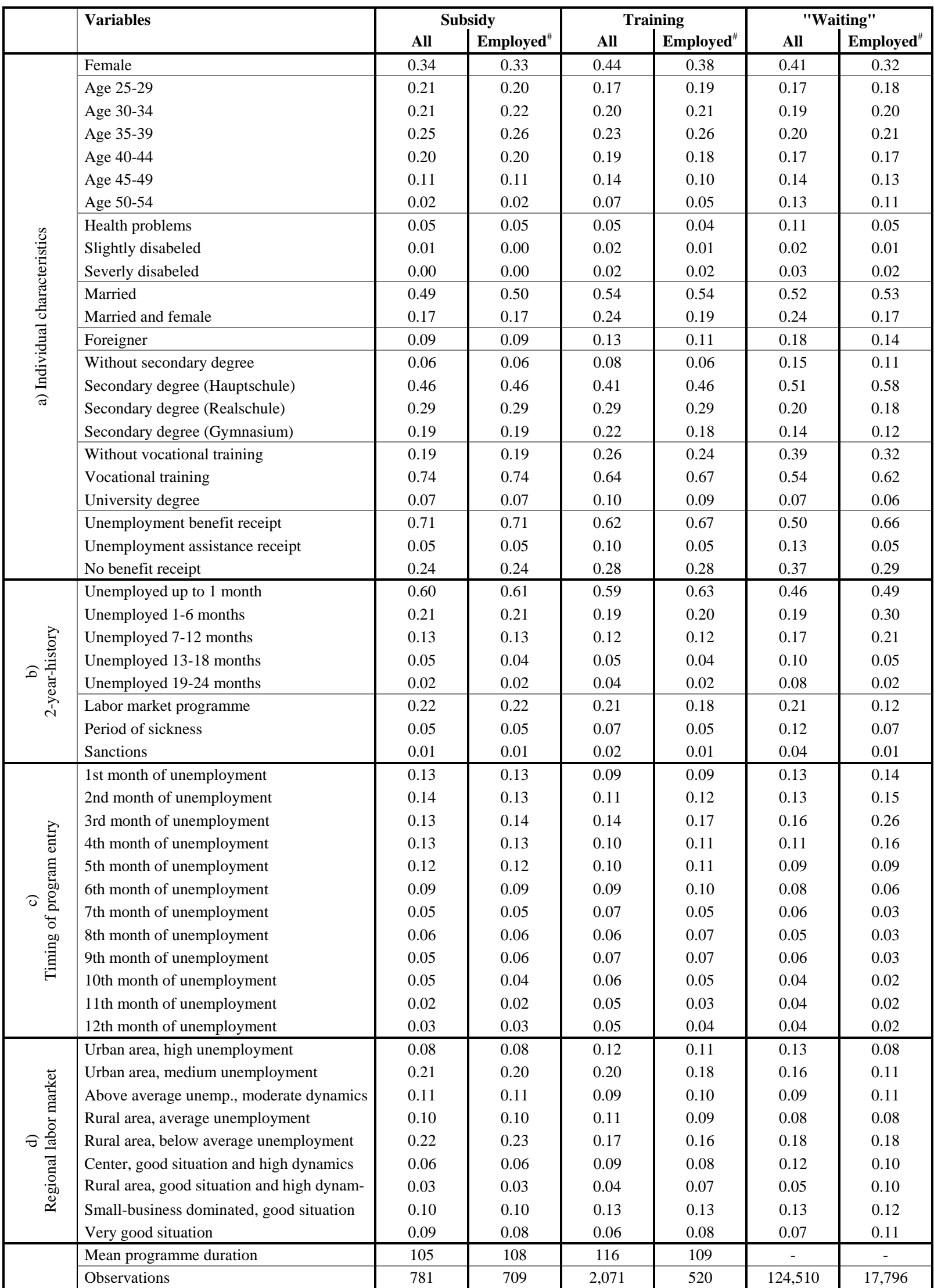

\#) Program participants that were employed one month after program end and "waiting” non-participants employed within one month after March 15, 2003.

Notes: Entries in subsidized employment (subsidy for training purposes) or further vocational training aimed at the provision of skills during March 2003. Only participants in programs with completed duration of up to 6 months.

Source: Own calculations, based on the TrEffeR data. 
Table 2: Average outcomes of treatment group $\mathrm{T}$ and matched comparison group $\mathrm{C}$ and average estimated treatment effects on the differentially treated (ATDT) of participation in program $T$ instead of program C, 3.5 years after program start

\begin{tabular}{|c|c|c|c|c|c|c|c|}
\hline \multirow{3}{*}{$\begin{array}{l}\text { Treatment } \\
\text { group (T) }\end{array}$} & \multirow{3}{*}{$\begin{array}{l}\text { Comparison } \\
\text { group (C) }\end{array}$} & \multicolumn{3}{|c|}{$\begin{array}{l}\text { Conditional on } \\
\text { employment }^{\#}\end{array}$} & \multicolumn{3}{|c|}{ Full sample } \\
\hline & & \multicolumn{2}{|c|}{$\begin{array}{l}\text { Average } \\
\text { outcome }\end{array}$} & \multirow{2}{*}{$\begin{array}{l}\text { ATDT of } \mathrm{T} \\
\text { relative to } \mathrm{C}\end{array}$} & \multicolumn{2}{|c|}{$\begin{array}{l}\text { Average } \\
\text { outcome }\end{array}$} & \multirow{2}{*}{$\begin{array}{l}\text { ATDT of T } \\
\text { relative to } \mathrm{C}\end{array}$} \\
\hline & & $\mathbf{T}$ & C & & $\mathbf{T}$ & C & \\
\hline \multicolumn{8}{|c|}{ Cumulated days } \\
\hline \multirow{2}{*}{ Subsidy } & Training & 878 & 866 & 11 & 844 & 544 & $300 * *$ \\
\hline & "Waiting" & 879 & 848 & $31 *$ & 844 & 459 & $385 * *$ \\
\hline \multirow{2}{*}{ Training } & Subsidy & 853 & 869 & -16 & 491 & 816 & $-326 * *$ \\
\hline & "Waiting" & 852 & 846 & 6 & 484 & 394 & $90 * *$ \\
\hline \multicolumn{8}{|c|}{ Employment share } \\
\hline \multirow{2}{*}{ Subsidy } & Training & 0.73 & 0.73 & 0.00 & 0.71 & 0.56 & $0.16 * *$ \\
\hline & "Waiting" & 0.73 & 0.67 & $0.06 * *$ & 0.71 & 0.45 & $0.27 * *$ \\
\hline \multirow{2}{*}{ Training } & Subsidy & 0.71 & 0.71 & 0.00 & 0.51 & 0.67 & $-0.16 * *$ \\
\hline & "Waiting" & 0.71 & 0.66 & $0.05 *$ & 0.50 & 0.39 & $0.12 * *$ \\
\hline
\end{tabular}

*) $\alpha=0.05$. **) $\alpha=0.01$.

\#) Program participants that were employed one month after program end and "waiting” non-participants employed within one month after March 15, 2003.

Notes: Entries in subsidized employment (subsidy for training purposes) or further vocational training aimed at the provision of skills during March 2003. Only participants in programs with completed duration of up to 6 months.

Source: Own calculations, based on the TrEffeR data. 
Table 3: Mean standardized bias (MSB) before and after matching, share in common support, largest weights in comparison group and significant odd ratios from Rosenbaum bounds analysis (RBA)

\begin{tabular}{|c|c|c|c|c|c|c|c|}
\hline $\begin{array}{l}\text { Treatment } \\
\text { group (T) }\end{array}$ & $\begin{array}{l}\text { Comparison } \\
\text { group (C) }\end{array}$ & before & after & Share in & pport & $\begin{array}{c}\text { Largest } \\
\text { weight } \\
\text { C } \\
\end{array}$ & $\begin{array}{l}\text { Odds } \\
\text { RBA }\end{array}$ \\
\hline \multicolumn{8}{|c|}{ Conditional on employment } \\
\hline \multirow{2}{*}{ Subsidy } & Training & 5.66 & 1.92 & 0.96 & 0.95 & 6.0 & -- \\
\hline & "Waiting" & 12.67 & 0.98 & 0.99 & 0.95 & 1.6 & (+) 1.2 \\
\hline \multirow{2}{*}{ Training } & Subsidy & 5.66 & 1.83 & 0.95 & 0.96 & 4.5 & - \\
\hline & "Waiting" & 10.69 & 0.99 & 0.99 & 0.97 & 1.0 & (+) 1.1 \\
\hline \multicolumn{8}{|l|}{ Full sample } \\
\hline \multirow{2}{*}{ Subsidy } & Training & 8.57 & 0.74 & 1.00 & 0.96 & 2.5 & $(+) 2.1$ \\
\hline & "Waiting" & 13.30 & 0.41 & 1.00 & 1.00 & 0.3 & $(+) 4.0$ \\
\hline \multirow{2}{*}{ Training } & Subsidy & 8.57 & 1.68 & 0.96 & 1.00 & 29.0 & (-) 2.1 \\
\hline & "Waiting" & 8.77 & 0.40 & 1.00 & 1.00 & 0.7 & (+) 1.8 \\
\hline
\end{tabular}

\#) Program participants that were employed one month after program end and "waiting” non-participants employed within one month after March 15, 2003.

Notes: Entries in subsidized employment (subsidy for training purposes) or further vocational training aimed at the provision of skills during March 2003. Only participants in programs with completed duration of up to 6 months. Odds have been calculated for shares in regular employment 3.5 years after program entry.

Source: Own calculations, based on the TrEffeR data. 
Figure 1: Only persons employed during one month after program start: Average outcomes of treatment group $\mathrm{T}$ and matched comparison group $\mathrm{C}$ and average estimated treatment effects on the differentially treated (ATDT) of participation in program $\mathrm{T}$ instead of program $\mathrm{C}$
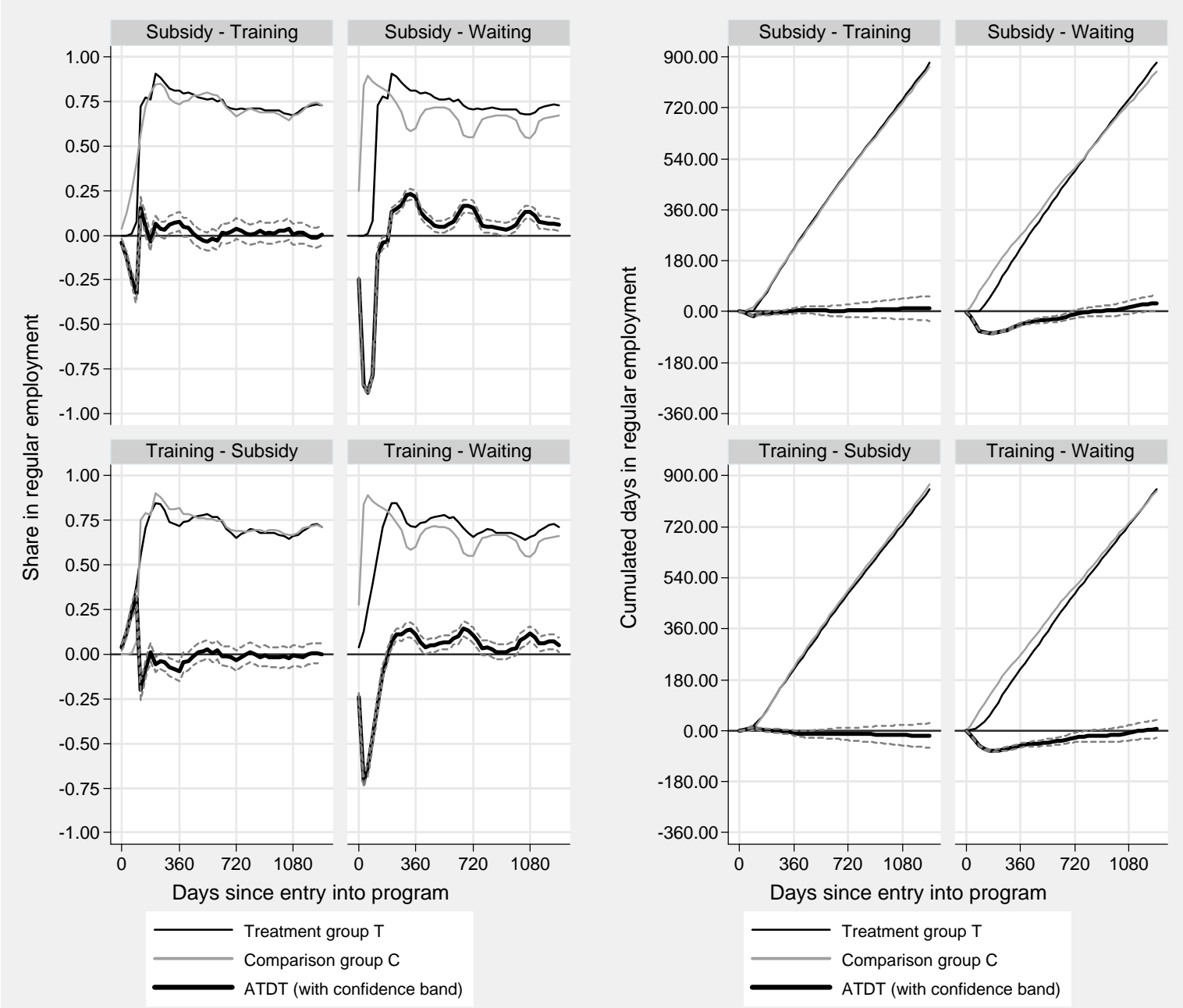

Notes: Entries in subsidized employment (subsidy for training purposes) or further vocational training aimed at the provision of skills during March 2003. Only participants in programs with completed duration of up to 6 months. For comparisons comprising subsidized employment, estimates should be interpreted as an upper bound on the effectiveness of wage subsidies.

Source: Own calculations, based on the TrEffeR data. 
Figure 2: Full sample: Average outcomes of treatment group $\mathrm{T}$ and matched comparison group $\mathrm{C}$ and average estimated treatment effects on the differentially treated (ATDT) of participation in program T instead of program $\mathrm{C}$
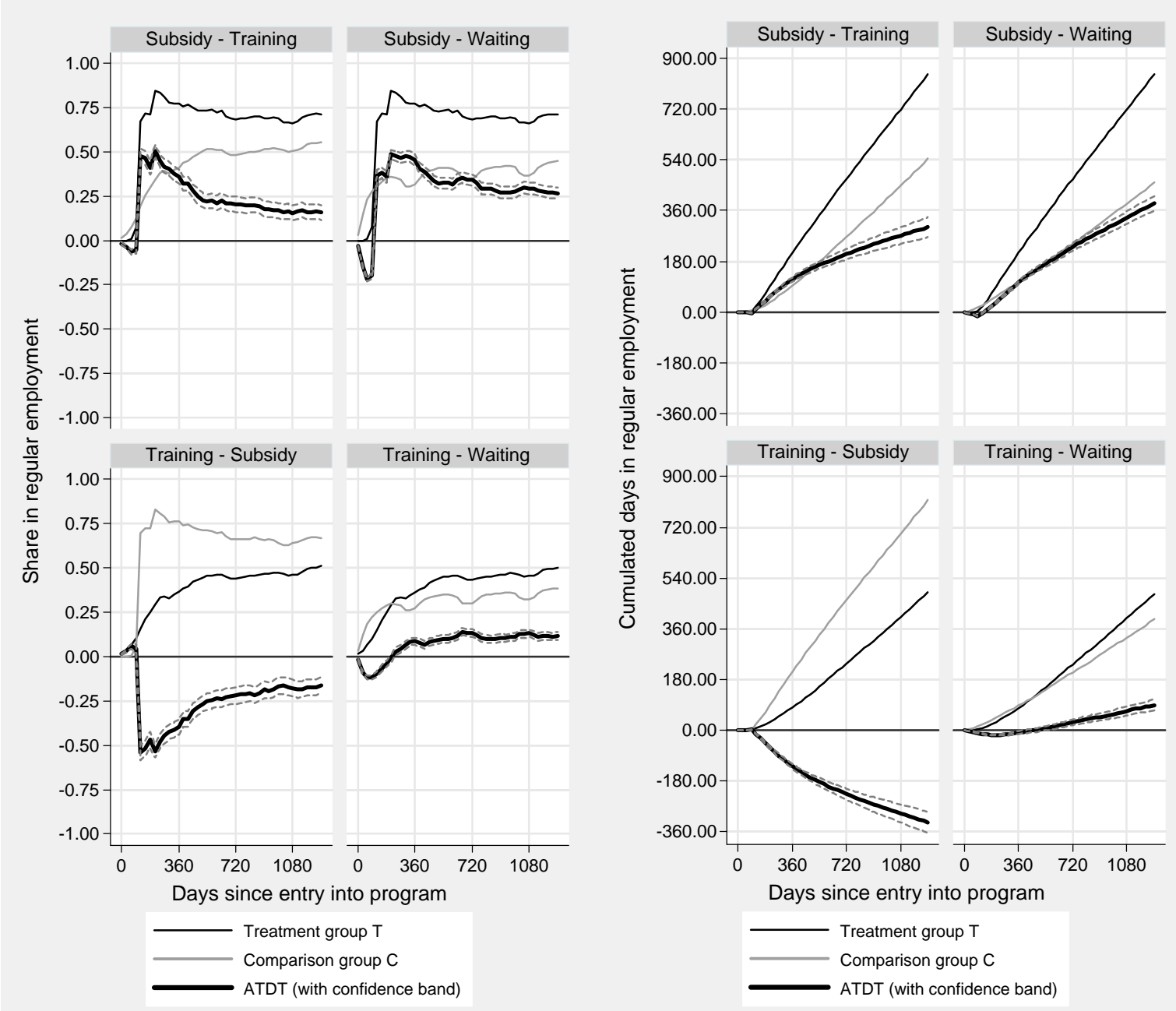

Notes: Entries in subsidized employment (subsidy for training purposes) or further vocational training aimed at the provision of skills during March 2003. Only participants in programs with completed duration of up to 6 months. For comparisons comprising subsidized employment, estimates should be interpreted as an upper bound on the effectiveness of wage subsidies Source: Own calculations, based on the TrEffeR data. 
